\title{
Lessons learned from a review of international approaches to spent fuel management
}

\author{
David Hambley ${ }^{1, *}$, Alice Laferrere ${ }^{1}$, W. Steven Walters ${ }^{1}$, Zara Hodgson ${ }^{1}$, Steven Wickham ${ }^{2}$, and Phillip Richardson ${ }^{2}$ \\ 1 NNL Central Laboratory, B170, Sellafield, Seascale, Cumbria, CA20 1PG, UK \\ ${ }^{2}$ Galston Sciences, Oakham, UK
}

Received: 2 November 2015 / Received in final form: 1 March 2016 / Accepted: 18 March 2016

Published online: 18 May 2016

\begin{abstract}
Worldwide, a variety of approaches to the management of spent fuel have been adopted. A review of approaches adopted internationally was undertaken to inform decision making on spent fuel management in UK. The review surveyed spent fuel storage and disposal practices, standards, trends and recent developments in 16 countries and carried out more detailed studies into the evolution of spent fuel storage and disposal strategies in four countries. The review highlighted that: (1) spent fuel management should be aligned to the national policy for final dispositioning of the fuel; (2) national spent fuel storage arrangements should deliver efficiency across all spent fuel management activities; (3) commercial and financial arrangements should ensure that spent fuel management decisions do not unnecessarily limit future fuel handling, packaging and disposal activities; (4) extended storage of spent fuel prior to packaging provides increased flexibility in the design of future packaging and disposal concepts. Storage of spent fuel over 100 years or more using existing technologies is technically feasible and operationally credible. Local factors such as existing infrastructure, approach to fuel cycle management, existing experience/capability and short-term cash flow considerations all influence technology selection. Both wet and dry storage systems continue to receive regulatory approval and are acceptable.
\end{abstract}

\section{Introduction}

There are a number of developments that have bearing on the management of spent fuel from power reactors in the UK. Domestically, these include the cessation of reprocessing, nuclear 'new build', the potential for reuse of UK plutonium and renewed progress in development of concepts for a geological repository. Worldwide, slow progress in the deployment of geological disposal facilities and reduced use of reprocessing have led to the need to extend storage periods for fuel and to store greater quantities of fuel.

Internationally, three different strategies have been adopted for fuel cycles:

- "Closed fuel cycle", where the spent fuel is reprocessed. Reprocessing has been deployed at an industrial scale in a number of countries with large nuclear power programmes (e.g. France, UK and Russia) and has been used by the majority of countries through commercial reprocessing services;

- "Open fuel cycle", where the spent fuel is not reprocessed and direct disposal of fuel has been chosen as the preferred option. This option has become more common over time.

\footnotetext{
* e-mail: david.i.hambley@nnl.co.uk
}

Geological repositories are not yet available, although a few countries are making significant progress towards opening a repository, most notably Sweden and Finland where operations are scheduled to start in 2027 and 2022;

- "Wait-and-see", where no decision has yet been made as to how fuel will be dispositioned. This option is most commonly associated with indecision or a failure to progress either a geological disposal site or a reprocessing facility.

The strategy adopted by a country impacts on the spent fuel management approach and the associated technological requirements. On the other hand, political considerations, public opinion and available infrastructure/ experience impact strongly on strategic decisions [1]. Given the range of strategies and technologies adopted internationally, it is important to understand the reasons why specific options have been selected in order to inform future decision making.

\section{The role of spent fuel storage}

Spent fuel storage is a necessary part of any nuclear fuel cycle. Ponds are used for storage and cooling of spent fuel after discharge from the reactor core to dissipate the very high decay heat associated with short-cooled fuel. Fuel 
must be stored in the reactor cooling pond until it can be transported safely and meets the conditions for acceptance for the next stage of the fuel cycle, which can be:

- reprocessing;

- geological disposal or;

- interim storage (wet or dry) at facilities on the reactor site (AR) or in centralised facilities away from reactor (AFR), pending onward shipment for reprocessing or disposal.

The two internationally accepted disposition options for spent fuel are reprocessing or direct disposal in a geological disposal facility (GDF). Irrespective of the strategy adopted, a GDF is necessary to dispose of heat generating waste, whether this is spent fuel from an open fuel cycle or the high level waste arising from a closed cycle.

Transportation of spent fuel is intimately linked with spent fuel storage, as fuel needs to be transported from the reactor pond to storage and from storage to the next stage of the fuel cycle. Thus, the impact of spent fuel storage on the transportability of fuel after storage is an important aspect when considering spent fuel management holistically.

In many cases, fuel needs to be moved between one configuration and another, e.g. for transport or for disposal. This has implications for fuel retrievability, operational and capital costs and waste generation. In some cases, fuel can be packaged for storage in a form that is also compatible with the requirements for transport and/or disposal. This has the potential to reduce handling and repacking operations, however to be successful it is vital that such systems are compliant with all subsequent operational requirements.

\section{Spent fuel storage systems}

A wide range of storage systems have been developed for power and research reactors, however the majority fall into one of four common types $[2,3]$.

Pool (Pond) - a pool is a facility which stores spent fuel in water. The spent fuel is usually supported in racks, baskets and/or containers which also contain water. Examples: AR ponds: Fukushima (Japan), Loviisa (Finland), Gösgen (Switzerland). AFR ponds: Sellafield (UK) (Fig. 1), La Hague (France), Clab (Sweden), GE Morris (USA).

Vault - a vault is a reinforced concrete building containing arrays of storage cavities suitable for containment of one or more spent fuel units. Examples include Wylfa facility (UK), MVDS facilities at Paks (Hungary) (Fig. 2), Fort St. Vrain (USA) and CANSTOR/MACSTOR at the Gentily-2 NPP (Canada).

Metal cask - a metal cask is a container with a bolted lid, similar to a large transport flask, designed either for storage only or for storage and transportation (dual-purpose casks). Multi-purpose casks for storage, transport and disposal have been proposed but no casks have yet been licensed for disposal. Examples include GNS CASTOR (Fig. 3); Transnucleaire TN-40; Westinghouse MC10.

Concrete cask - a concrete cask has a thick, welded steel canister, which is cooled by natural convection. The canister is inserted into a concrete overpack which provides

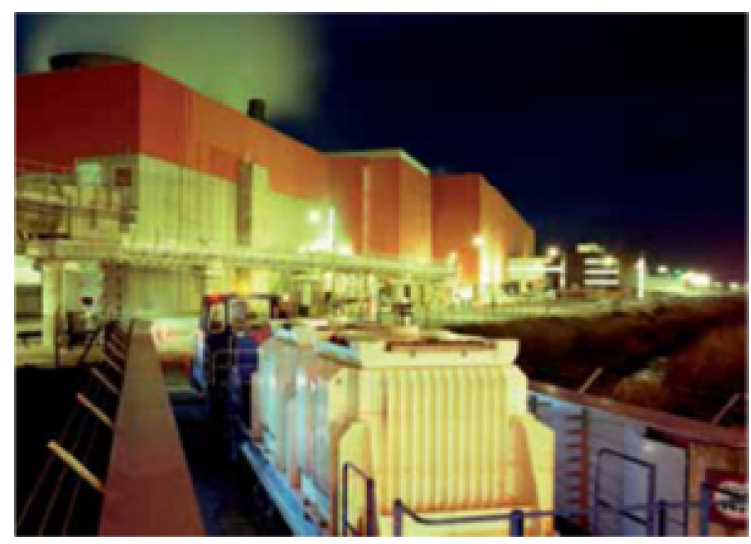

Fig. 1. Centralised storage pond (Courtesy of Sellafield Ltd).

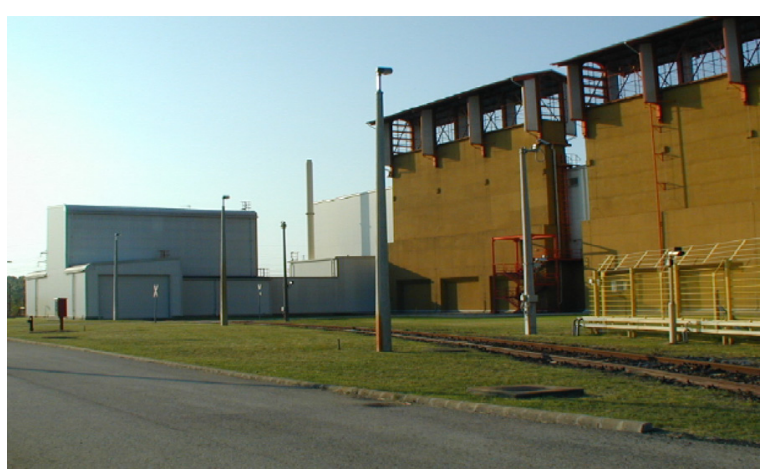

Fig. 2. Dry vault store [4].

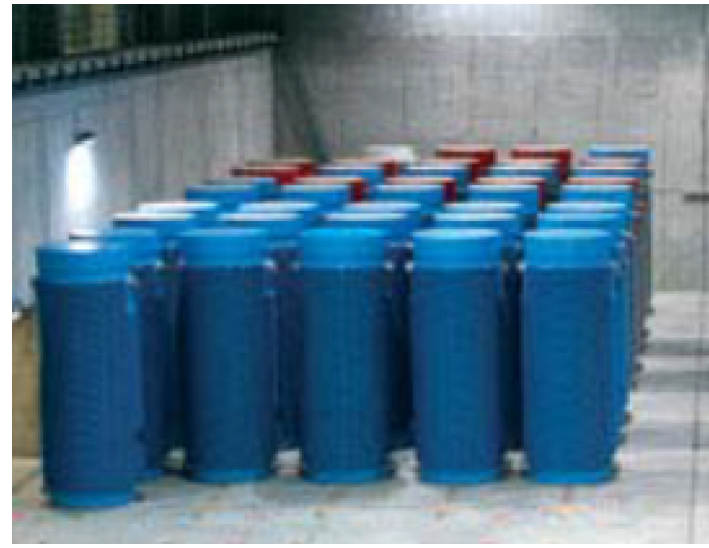

Fig. 3. Metal casks [5].

shielding. The canister can be stored in either vertical (Fig. 4) or horizontal orientation (Fig. 5). Examples include Holtec HiStorm, Sierra Nuclear's VSC (USA); Ontario Hydro's Pickering concrete dry storage container (Canada) and NuHoMS (USA).

Silos - a silo is similar to a vertical concrete cask, except that there is no cooling flow inside the monolithic structure. This form of storage is only, therefore, suitable for low heatoutput fuel. Examples include New Brunswick Power's Point Lepreau (Canada) (Fig. 6), Embalse (Argentina). 


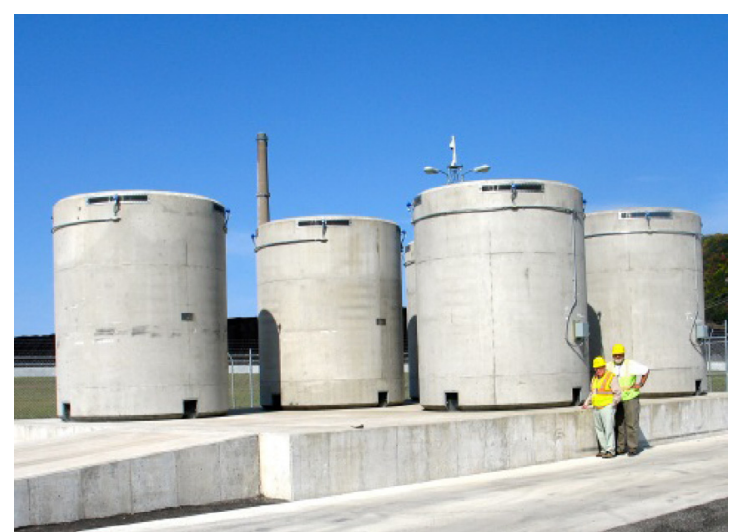

Fig. 4. Vertical concrete casks (Courtesy of NAC International).

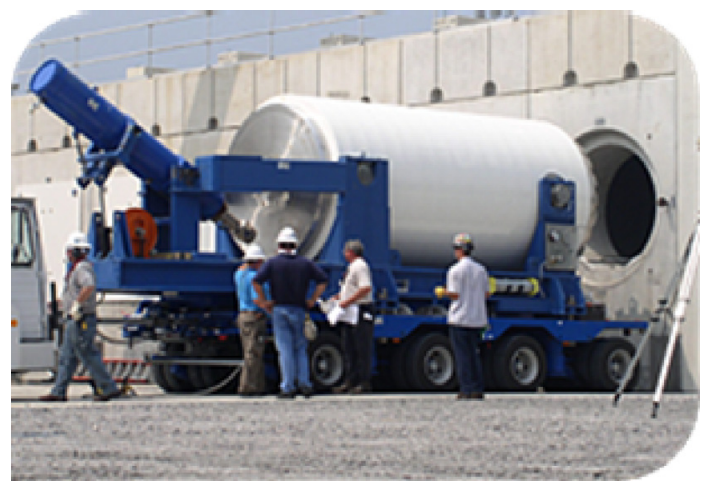

Fig. 5. Loading a canister into a horizontal concrete storage module (Courtesy of Areva TN Inc).

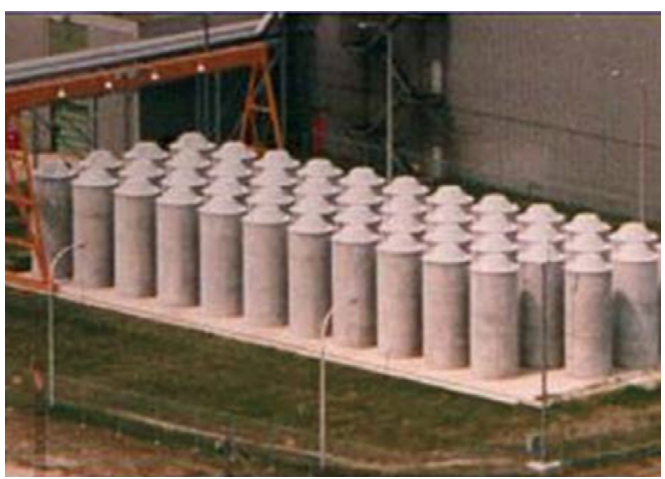

Fig. 6. Silos [6].

All fuel entering dry storage needs to be dried to remove excess water for the fuel, so as to avoid pressurisation and corrosion during storage. Dry spent fuel storage was developed for short-term storage until GDFs became available and is a less mature technology than pond storage. Dry storage system designs have developed substantially over the past 20 years. Designs rely on passive cooling, which reduces operation and maintenance requirements and costs; however, periodic surveillance is still required. Additional equipment and infrastructure are required to load fuel and different design variants have been developed for different fuel types [7].
Fuel is only recoverable from metal/concrete casks systems when reactor ponds remain operational, as reactors and most dry storage facilities do not have shielded facilities in which the radiation from the stored fuel can be contained. Fuel in canister-based systems is not intended to be recovered, however the trend towards larger payloads has made disposal more problematic. Comprehensive ageing management plans for long-term dry storage are now under development, which may lead to further system design evolution or enhanced monitoring and surveillance requirements.

Pond designs have also evolved, with modern designs having passive cooling systems and much greater resistance to external events [8].

With increasing length of storage, the potential need for fuel inspection to provide assurance of the condition of fuel after storage and the requirements for demonstrating retrievability of fuel are under renewed consideration. The certainty that AR fuel storage will continue long after the reactors and associated fuel handling infrastructure have been dismantled also needs to be factored into decision making.

The recycling of $\mathrm{Pu}$ into $\mathrm{MOX}$ for thermal reactors is not widespread and hence spent fuel storage systems have been developed with $\mathrm{UO}_{2}$-based fuels (UOX) in mind. Although there are differences between spent MOX and UOX fuel, the challenges arising from the storage of MOX are identical in nature, if not in intensity, to those from UOX and irradiated MOX in LWR systems has been safely managed out of reactor in both dry cask and ponds [5,9].

The primary challenges with MOX fuels are:

- higher decay heat per GWe produced compared to UOX, which needs to be removed by the cooling systems. This requires a longer cooling period and/or lower payload to meet heat load/dose rate requirements for storage, transport, reprocessing and disposal;

- higher neutron activity due to minor actinide content. This requires additional neutron shielding and introduces additional operational restrictions compared with spent UOX fuel storage;

- higher fissile content than UOX, although actual content depends on irradiation history. This affects the density of storage and extent of criticality control measures required;

- higher He generation leading to increased internal pressurisation of fuel cladding and increased lattice swelling effects during long-term storage/disposal;

- mixing of spent MOX fuel with spent UOX fuel can be effective in managing the effects of increased heat generation and radiation associated with MOX fuel, so long as the proportion of MOX fuel remains low.

\section{International review}

Sixteen country nuclear profiles and their approaches to spent fuel management have been reviewed to build a picture of the range of spent fuel management strategies and practices that are currently in use. The countries 
studied were: Belgium, Canada, China, Finland, France, Germany, Hungary, Japan, Netherlands, Russia, South Korea, Spain, Sweden, Switzerland, United Kingdom and United States of America [1].

Data from the review has been summarised in Table 1. 'Fuel type' and 'Fuel requirements' correspond to the fuel loaded in the nuclear power plants. 'Storage capacity' and 'Storage quantities' correspond to the capacity of all storage facilities, AR and AFR, and the quantities of spent fuel in those facilities. 'Storage arisings' is the amount of spent fuel arising in long-term storage facilities per year. Unless specified, fuel requirement, storage capacity, spent fuel cumulative in storage and spent fuel arisings are based on 2012 data [10]. Interim storage 'type' and 'location' have been codified as predominantly 'wet' or 'dry' and 'AR' or 'AFR'. For countries with only one reactor, 'centralised' is used, instead of AR.

It is clear that national spent fuel management strategies are influenced by expectations at the time investments were made (e.g. availability and location of a reprocessing facility or a repository), the national reactor fleet, including reactor types, geographical locations and the transport infrastructure, and the potential for economies of scale. Therefore, there is no exact precedent to follow.

The strategy adopted by different countries influences storage type and requirement. For example, countries that have chosen reprocessing tend to mostly have AFR wet storage. Countries where disposal of spent fuel is the chosen strategy, or where back-end management is still undecided, tend to have AR dry and/or wet storage. Sweden is the only country which has decided to dispose of spent fuel and has a large centralized wet facility AFR: the CLAB facility.

The quantities of spent fuel in storage may be compared with storage capacities. Countries with spent fuel quantities close to storage capacities plan to extend their capacity by adding ponds (Finland), vaults (Hungary) or dry casks (Spain) by 2015. The modular dry vault storage in the Netherlands will reach full capacity by 2021 [11]. Only Belgium does not plan on extending storage capacity in the coming years, but reprocessing is still an option being considered.

For most countries with a reprocessing strategy, fuel requirements for continued operation of the nuclear plants are higher than spent fuel arisings in storage (i.e. France, Japan). Only the UK has a higher spent fuel annual arising than fuel requirement, principally because part of its reactor fleet currently being decommissioned. For countries with a disposal strategy, fuel requirements are close to spent fuel arisings apart from Spain, which has higher arisings due to the decommissioning of Garona.

State and political endorsement of deploying reprocessing (domestically or abroad via commercial fuel service arrangements) is a key enabler as experience to date indicates that the will and investment from a commercial enterprise alone is insufficient to sustain such an activity. Significant effort and know-how are required to realise a plant-scale reprocessing operation from a position of scientific knowledge, which could be a barrier to deployment; equally, loss of skills and facilities and the difficulties in recovering from a period without plant-scale reprocessing

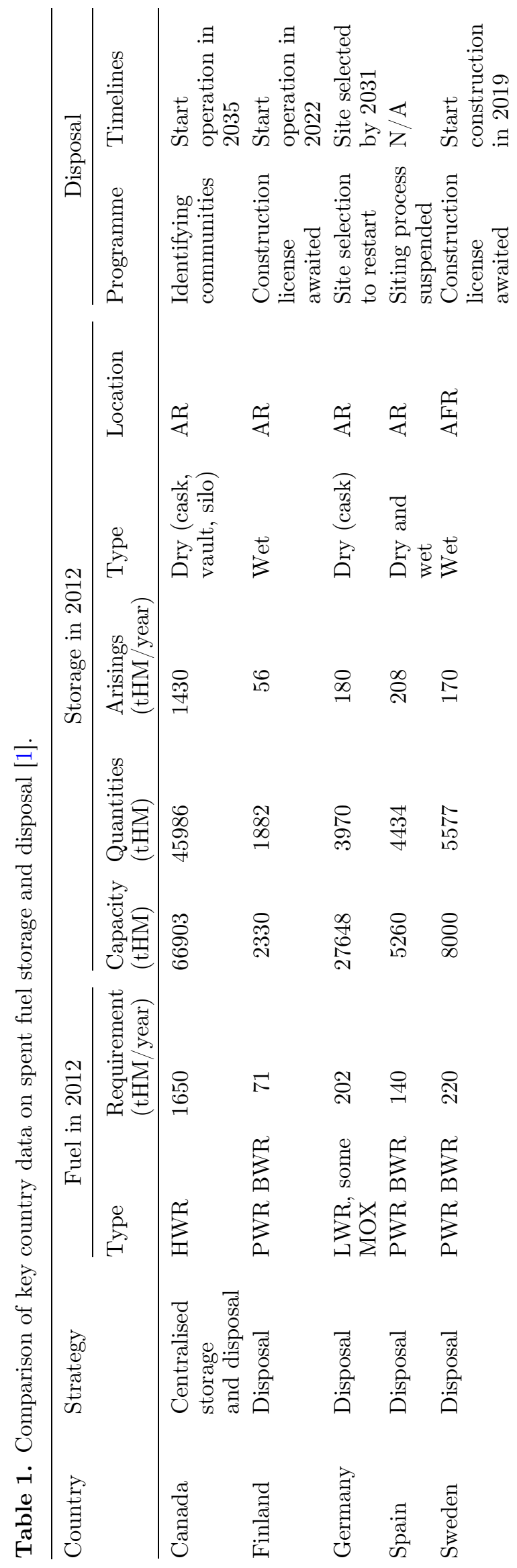




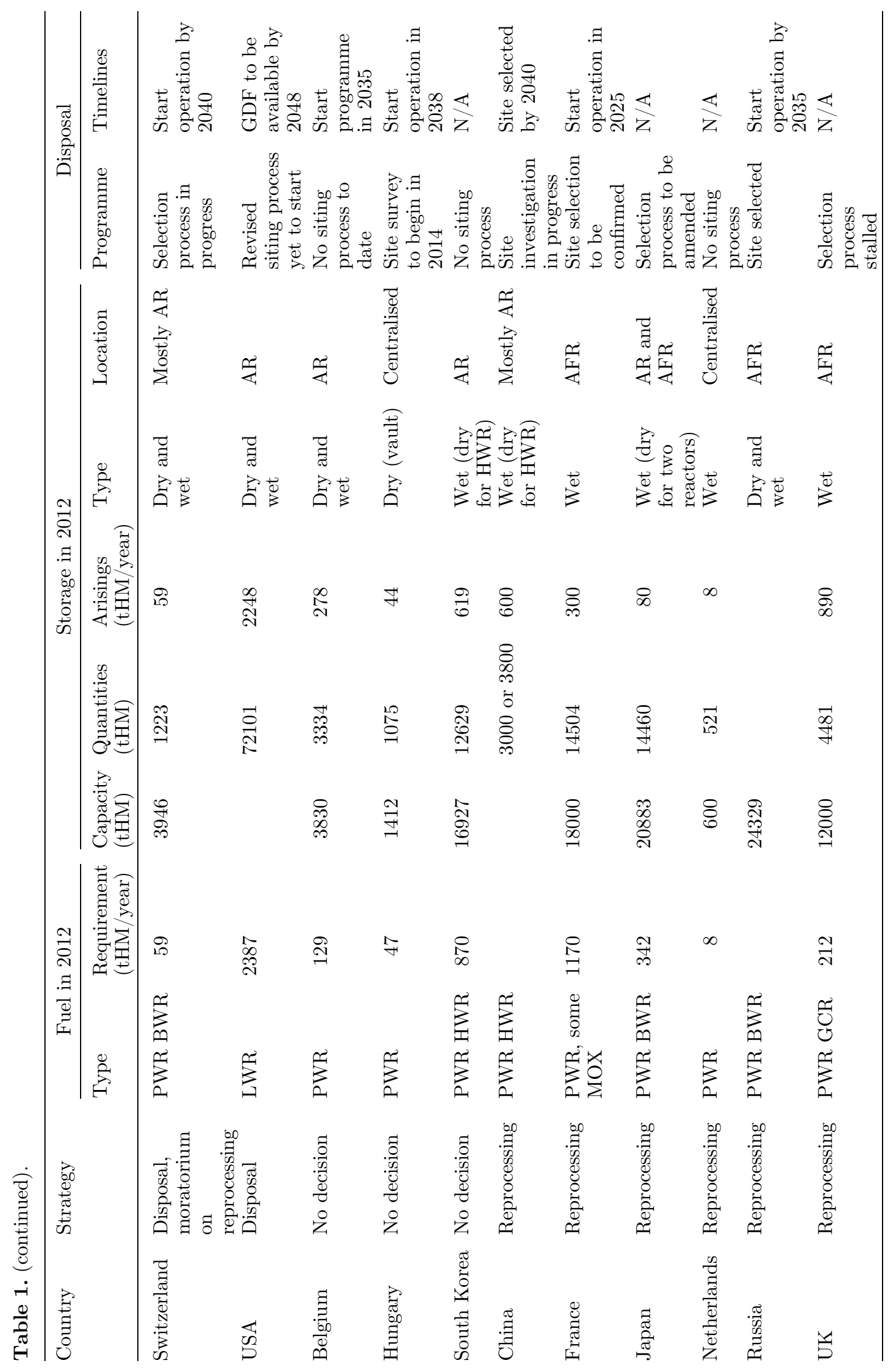


would be a barrier to a subsequent deployment of reprocessing. Japan's experience would indicate that even with its extensive nuclear experience and technical knowledge, the establishment of an expert buyer capability does not guarantee quality or efficiency of procured products and services.

Most countries have started a disposal programme and are selecting or investigating suitable sites. Finland, France, Russia and Sweden have chosen a site. Only Belgium, the Netherlands and South Korea have not started a site selection process. Progress has been greatest in Sweden and Finland.

From the survey of individual nations, it is apparent that some nations have a long-term vision or strategic plan for the nuclear fuel cycle whereas a number of others do not. In order to provide greater understanding about the development of these differences, further work was undertaken to examine the impact of having long-term plans for spent fuel management in countries that have them and compare this with countries without such visions or plans.

Some of the best examples of long-term visions or plans are found in Sweden, Finland, France and the Netherlands. The arrangements in place in these countries were examined to identify any common threads and to assess what impact these visions or plans have had on practical arrangements for storage and disposal of spent nuclear fuel.

Examples of countries without any current long-term vision or plan include Germany and the USA. These countries have (in the past) had plans, but for various reasons, mainly political, the plans have been disrupted and spent fuel management is now much more reactive, responding to external factors rather than based on a well-defined vision or strategy. The effect of the lack of longterm stability in these countries was examined to identify common threads and their impact on spent fuel management practices.

\section{Key messages}

This review has shown that the way in which liabilities are distributed between organisations involved in the generation, management and disposal of spent fuel has a significant effect on the effectiveness of spent fuel management. In democratic countries, the greatest stability in back-end fuel management, and greatest efficiency and integration, are associated with countries in which governments have set policy, strategy and regulation, leaving commercial entities with the integrated liability for storage and the development, licensing and implementation of the required disposal facilities.

To achieve overall cost effectiveness, spent fuel management should be aligned so as to meet the technical requirements of the national policy for the final dispositioning of the fuel.

Given the long timeframes associated with GDF site selection and the management life-cycle associated with nuclear fuel, policy-making for effective delivery of the strategy should be directed at developing a robust and resilient overall approach, rather than focusing on short-term efficiency. Where public acceptance is important, clear separation between regulation and delivery of storage and dispositioning supports effective long-term delivery.

At a national level, policy decisions can constrain or incentivise particular forms of spent fuel management. Therefore, it is prudent for national decision makers to consider the factors affecting storage options (e.g. centralised versus decentralised) and the financial, social and environmental effects of different strategies. Commercial and financial arrangements should ideally be constructed to ensure that, at each stage of the spent fuel life-cycle, spent fuel management decisions do not unnecessarily preclude future management options or increase the costs of subsequent activities leading to final dispositioning of the fuel.

Where more than one organisation is responsible for spent fuel storage, disposal and any intermediate processing, there should be commercial agreements between those responsible that incentivise efficient management of spent fuel to its final end point, in preference to maximising the efficiency of individual stages of spent fuel life-cycle. Policy makers in setting the national policy framework and regulation should therefore take organisational responsibilities in account when designing national approaches to spent fuel management so as to best incentivise all actors to provide efficient and effective dispositioning of spent fuel.

On a technical level, storage of spent fuel for over 100 years or more using existing technologies, or foreseeable evolutions of them, is feasible and credible. Over such timescales, all storage systems and supporting infrastructure will need to be refurbished and replaced as they degrade. The time interval between major refurbishment or replacement remains uncertain but it would be reasonable to expect a 50to 100-year replacement period based on current systems, by analogy with highly active waste storage facilities.

The use of multiple approaches to fuel storage, and continued evolution of the storage facility designs indicate that there is no single best storage technology, and that local factors such as existing infrastructure, size of national spent fuel inventories, approach to fuel cycle management, existing experience/capability, geographical factors and short-term cash flow considerations all influence technology selection.

Both wet and dry storage systems continue to receive regulatory approval and are acceptable in terms of safety and environmental impact and operational practicality.

Dry storage is less mature than wet storage and issues related to storage beyond 20 years, including post-storage transport and impact on disposal systems, are now being addressed. The transition to dry storage results in the fuel experiencing a period of higher temperatures and this may affect fuel performance. The extent of any degradation of the spent fuel is currently a topic of research and assessment. Some changes to system design can be anticipated as a result of this work and may increase capital or operating costs. Dry storage systems generally provide small incremental storage capacity and lower shortterm cash flow requirements than ponds or vaults [12]. Operational costs during reactor operational phase are low, but recent analysis by US GAO have shown a large increase in AR operational costs once reactors shutdown [13]. 
Wet storage has been successfully employed for many decades and is a more mature technology. Nevertheless, designs are evolving to increase the levels of passive safety and resistance to external and malicious events. Wet torage provides easier monitoring of fuel conditions and greater flexibility in post-storage transportation and packaging [8]. Provided pond water quality can be maintained over the required storage period, fuel quality is likely to be assured. However, traditional pond systems require active management and higher levels operational support.

The thermal output of spent fuel is critical to the design and overall performance of a spent fuel GDF. The following key factors in spent fuel management have been identified as being critical to the disposability of spent fuel:

- age, burnup and thermal output of spent fuel constrain the temperature evolution of the disposal system with time, although this will also be influenced by host rock thermal conductivity and engineered barrier system design. Acceptable thermal output often determines how long an interim storage period is required and may place constraints on design of the waste packages. In general, it is necessary to store spent fuel for longer periods for direct disposal than for reprocessing;

- if spent fuel becomes degraded through long-term storage, either wet or dry, this may compromise disposability by making it incompatible with the selected packaging concept or handling infrastructure, and may require additional package finishing prior to disposal;

- the way spent fuel has been packaged for long-term dry storage may control the subsequent packaging or disposal concepts that are viable. No potential site for a spent fuel GDF exists in the UK at the current time and therefore the host geology remains unknown. Generic disposal concepts and designs exist for a number of general geological environments based on overseas design concepts, but none are compatible with modern dry storage cask designs.

Depending on the storage systems used and fuel condition at the end of storage, an export facility may need to be built in order to ensure that fuel is exported in packages suitable for transport or transport and disposal. Such a facility may need to include capabilities for some or all of the following: fuel drying, opening sealed dry-stored packages, repackaging spent fuel in disposal containers and remediating degraded packages. The scope of any onsite facility will also depend on decision made about the capabilities at a GDF.

In addition to the technical requirements to ensure the long-term integrity of fuel and storage systems, it is important that organisations retain the required level of technical capability and information or the duration of storage, so as to ensure that post-storage activities are managed safely.

This work was funded by the Nuclear Decommissioning Authority.

\section{References}

1. A. Laferrere, D. Hambley, W.S. Walters, Z. Hodgson, S. Wickham, P. Richardson, Review of international approaches to the management of spent fuel, NNL 12635, 2014

2. IAEA, Survey of wet and dry spent fuel storage, IAEATECDOC-1100, 1999

3. EPRI, Industry spent fuel storage handbook, EPRI report No. 1021048, 2010

4. Z. Husak, J. Bencze, Storage of spent nuclear fuel in MVDS of PAKS NPP, http://www.dysnai.org/Reports/2000-2004/ 2004/3.pdf, accessed February 2016

5. H. Völzke, Dry spent fuel storage in dual purpose casks- Aging management issues, in INMM Spent Fuel Management Seminar XXVIII, Arlington, VA, January 14-16, 2013 (2013)

6. M. Petrovic, J. Hashmi, P. Eng, Single storage canister to MACSTOR - 14578 Canadian solution and experience in responsible spent fuel management, ${ }^{\circledR}$ in WM2014 Conference, Phoenix, Arizona, USA, March 2-6, 2014 (2014)

7. IAEA, Operation and Maintenance of Spent Fuel Storage and Transportation Casks/Container, IAEA-TECDOC-2532, 2007

8. U. Appenzeller, External spent fuel storage facility at the nuclear power plant in Gösgen, in Technical Meeting on SNF storage options, 2-4 July 2013 (IAEA, Vienna, Austria, 2013)

9. IAEA, Status and advances in MOX fuel technology, IAEATRS-415, 2003

10. OECD/NEA, Nuclear energy, NEA No. 7162, 2013

11. J. Hart, A.I. van Heek, The effect of electricity generating park renewal on fossil and nuclear waste streams: the case for the Netherlands, Kernenergie: International, 2008

12. IAEA, Costing of spent nuclear fuel storage, Nuclear Energy Series No. NF-T-3.5, 2009

13. United States Government Accountability Office, Spent nuclear fuel management outreach needed to help gain public acceptance for federal activities that address liability, GAO-15-141, 2014 